\title{
Appraisal of Assessment Skills of Basic Science Education Teachers: Towards Quality Assurance
}

\author{
Elizabeth I.D. Offor, ${ }^{1, *}$ \\ ${ }^{1}$ Department of Physical Science Education, Faculty of Education, Imo State University, Owerri Imo State, Nigeria \\ *Correspondence: Department of Physical Science Education, Faculty of Education, Imo State University, Owerri \\ Imo State, Nigeria. Tel: 234-803-709-1426. E-mail: lizoffor@yahoo.com
}

Received: March 25, 2014

Accepted: May 7, 2014 Online Published: June 10, 2014

doi:10.5430/wje.v4n3p68

URL: http://dx.doi.org/10.5430/wje.v4n3p68

\begin{abstract}
Assessment is a very important programme in education. Assessment information shows the level of achievement of objective. Important decisions are made about the learner and education system based on results of assessment. Whatever the parents know about quality of education is through the assessment reports of their wards. Considering its primordial role in education, it is not safe to conduct assessment in a haphazard manner. Assessment requires some levels of competency to be able to ask the right questions and elicit the desired responses. Educational system in Nigeria has been accused of poor quality due to poor skills acquisition of the graduates. Can the problem be traced to wrong mode of assessment? Primary education is the foundation- laying stage of which if the problem is detected and corrected at this level, quality would be assured. This is the reason the researcher carried out study to ascertain the assessment competence of basic (Primary 1-6) teachers who assess and certify pupils that move to secondary level. 93 copies of lesson plan written by the teachers were critiqued in terms of adequacy of specific objectives and evaluation questions meant to be used in ascertaining the achievement of the objectives. 4 research questions guided the study. Findings showed lack of direct link between the specific objectives and the question items used in assessing them. There was preponderance of assessment questions at the knowledge level of cognitive domains. It was recommended among others that teachers need capacity building in the area of assessment of learning. Again, the current arrangement where a single teacher teaches all the subjects should be reviewed.
\end{abstract}

Keywords: introduction; assessment skills; method; results; recommendations; references; appendices

\section{Introduction}

Assessment which comes under different appellations- School Based Assessment (SBA), Continuous Assessment (CA) etc is carried out in schools to ascertain the extent to which learning has taken place in the learner. Information arising from assessment is used to gauge the learners' academic strengths and weaknesses, take decision regarding selection for a programme, classification, placement, managing instruction or certification (Ojerinde 2011). Basically, assessment information helps the teacher to ascertain how much learning has occurred in the learner and consequently determines how good the amount of learning is in comparison with the set objectives (Yoloye 2011). In addition, communities rely on the assessment results to judge the quality of educational system while the policy makers determine whether the public schools meet the goals and aspirations for which they are set up using the same measure. To this extent assessment of learning represents a commitment to high academic standards and school accountability. Though, this depends on the credibility of assessment procedures that yielded the information used for such decisions. Writing on the indicators of quality assurance in education Erinosho (2011) identified assessment and feedback mechanism as vital features of quality. Corroborating Okwilagwe (2010) maintain that assessment is central to achieving excellence in education and this largely depends on quality measures applied. Given that assessment is all this important in education, policy makers had always insisted on modalities that ensure assessment yields valid results.

The Federal Ministry of Education guidelines on continuous assessment prescribed (among others) that assessment should feature variety of strategies such as tests, projects, quizzes, peer assessment strategies and other techniques in measuring abilities in the cognitive, affective and psychomotor domains of the learner. This is to get the true reflection 
of the learners' ability by collecting information about the learner in different areas (Ojerinde 2011). It is the aim of the Universal Basic Education (UBE) that at the completion of Basic 6 the pupils would have acquired appropriate levels of literacy, numeracy, manipulative and life skills as well as foundation for life-long learning (FGN, 2004). Experience showed a mismatch between the teachers' academic reports of the pupils and the pupils' abilities in real life settings. Even when the pupils continued their education to upper basic level (Junior Secondary) percentage of their performances in the junior School certificate examination (JSCE) had not been encouraging as shown in table one of the appendices. The data in table one showed that students' performances were more at the pass and failure grades than distinction and credit grades. Few percentages of the students made it at the distinction and credit level (13.11\%) while the pass and failure grades amounted to $41.03 \%$ and $32.75 \%$ respectively within the review period. Since the quality of performances decreases from distinction down to failure grades, it implied that the results were dismal. Yet, these students had been reported to be academically sound by their lower Basic (Primary 1 to 3 ) and middle Basic (Primary 4 to 6) classroom teachers.

Table 1. Percentage of Passes and Failures at the JSCE (in BST) for a 4-Year Period

\begin{tabular}{lllll}
\hline Year & D & C & P & F \\
\hline 2011 & 10.2 & 21.1 & 41.5 & 27.2 \\
2010 & 9.8 & 16.5 & 42.8 & 30.9 \\
2009 & 5.4 & 14.7 & 38.6 & 41.3 \\
2008 & 8.3 & 18.9 & 41.2 & 31.6 \\
Average & 8.43 & 17.80 & 41.03 & 32.75 \\
\hline Total Average & 13.11 & & & \\
\hline
\end{tabular}

D-Distinction, C-Credit, P-Pass, F-Fail

Source: Examination Development Division, Ministry of Education, Imo State.

It is worrisome that it is rare these days to see a pupil repeating a class in primary schools (basic 1 to 6 ) despite the fact that assessment is meant to sort learners in terms of those who have reasonably achieved the objectives and those who are yet to do so. Pertinent questions are: do the teachers have the skills of assessment, are the tools defective? How adequate is the assessment in accordance with policy stipulations? It is the hope that findings of this study will help in finding answers to these questions.

\section{Assessment Skills}

Skill has to do with ability to do something well. It involves having a good knowledge of the component parts of a thing. Thus, adequate knowledge of process of assessment translates to the display of same in the classroom. Assessment on the other hand entails observing the pupils performance by creating a situation to which the pupils react in certain ways. Most times, when the assessment tool is defective it arouses the kind of reaction different from what is intended. In this study the assessment skills of the teacher is looked at in terms of the ability of the teacher to identify and state objectives relevant to a given subject matter and consequently formulate assessment questions based on the objectives. If the assessment questions are not related to the specific objectives, it depicts poor assessment skills. Each specific objective should have mode of assessment which helps to ascertain whether the objectives are achieved or not. If the modes of assessment do not cover the number of specific objectives set for the lesson then there will be discrepancies between plan and action. On the other hand, specific objectives should be stated in the cognitive, affective and psychomotor domains of behaviour and these should be accompanied by assessment items. A teacher who is able to use the right action words to state objectives and assessment items at the level of intellectual functioning needed at any given time exhibits good assessment skills. The list is endless but suffice it to say that adequate knowledge of subject matter enables the teacher to plan well his or her assessment procedures.

For uniformity, monitoring of operations and quality assurance, the national policy on education (FGN 2004, p. 14) stipulated the goals of basic education which formed the bedrock of the contents teachers teach and assess in schools as follows;

Inculcate permanent literacy and numeracy and ability to communicate effectively.

a) Lay a sound basis for scientific and reflective thinking.

b) Give citizenship education as basis of effectives participation in and contribution to the life of the society.

c) Mould the character and develop sound attitude and morals in the child. 
d) Develop in the child the ability to adapt to the child's changing environment.

e) Give the child opportunities to developing manipulative skills that will enable the child function effectively in the society within the limits of the child's capacity.

f) Provide the child with basic tools for further educational enhancement, including preparation for trades and crafts of the locality.

Enumerating the obligations of the teachers, the Teachers Registration Council of Nigeria (TRCN 2004, Chapter two 9d.) identified evaluation of learners' performance as the crucial functions of the class teacher in achieving standards in education. The 9-year basic education curriculum document further simplified the goals into performance objectives and evaluation guide (Revised edition, 2012). These ease the job of the teacher should he/she find it difficult ascertaining what the objectives and mode of evaluation should be.

\section{Specific Objectives}

Every human activity has underlining motives and so does teaching. Specific objectives are the reasons for teaching. Display of good assessment skills begins with ability to state objectives correctly, followed by selection of appropriate assessment items. Thorndike and Hagen (1977) posited that teacher-made tests are often times vague, ambiguous and lack purpose. Indeed, teacher -made tests have been variously criticized by experts in test construction as being deficient in the coverage of content and objectives (Anikweze 2012, Ezeudu, Agwagah and Agbaegbu 1997). Perhaps, if teachers employ many strategies in assessment, information from many sources might help to cushion the effects of inadequate test items. However teachers should determine the purpose of any assessment. Nwana (2007) noted that teachers' assessment border mainly on cognitive domain to the expense of affective and psychomotor domains. Ogomaka (2009) had advised that teachers should set questions ahead of time of assessment with the aim of revisiting them a second time and also give colleagues to read. During these processes items that need to be reframed, modified or dropped outrightly would be identified. This is done to validate the teacher made tests.

Nwana (2007) observed that teachers usually wait till the time of assessment to hurriedly copy the questions that authors of textbooks asked at the end of each chapter without minding whether they serve the purpose or not. Preparing for assessment demands a commitment to duties. The other aspect of weakness was in the area of marking and award of marks which are obviously affected by the generosity and severity tendencies of individual teacher, and which make comparison of standards across classes and school almost impossible. Action words are behavioural terms that indicate the task of the question. Their function is to indicate the level at which performance is expected. For instance, the levels of cognitive, affective and psychomotor domains and the behavioural terms that depict each level are as indicated in tables 2, 3, and 4. These behavioural terms serve as guides to an independent assessor of the relatedness or relevance of assessment instruments to the specific objectives. Hence, Ivowi, (2009) explained that the action words such as 'define' and 'explain' are very different in context and expectations. For while the former (define) demands less intellectual obligation than the latter (explain) it will be unfair to award the same marks for both of them. Define represents tasks at the knowledge level while explain demands performance at the level of understanding. This implies that as the tasks increase down the hierarchy so does the reward for attainment of the skills differ. Given that the factors that constitute good assessment skills are many and varied, and might not all be handled in a single assessment or study, it is important to limit the scope of assessment skills in this paper.

Table 2. Levels of Cognitive Domain and the Behavioural Terms Used in Stating Specific Objectives

\begin{tabular}{ll}
\hline COGNITIVE LEVEL & BEHAVIOURAL TERMS \\
\hline Knowledge & Define, list, mention, recite, name, state, label, identify, enumerate etc \\
Comprehension & Explain, differentiate, illustrate prepare, determine, inter compare etc. \\
Application & Relate, deduce, apply, transfer, classify, suggest supply etc \\
Analysis & Categorize differentiate, analyze critique, breakdown, examine etc. \\
Synthesis & Produce, organize, compose derive, combine, invent, make etc. \\
Evaluation & Consider, judge, appraise, justify interpret, defend, value, assess etc \\
\hline
\end{tabular}

Adapted from IWU, Mbadiugha, Ugor and Ikwuanusi (2011). 
Table 3. Affective Domain and Associated Behavioural Terms

\begin{tabular}{ll}
\hline LEVEL & BEHAVIOURAL TERMS \\
\hline Receiving & Accept, respond, receive, share etc. \\
Responding & Comply, practice, support, value, favour, form attitude etc \\
Organization & Sort, organize formulate, synthesis generate, produce integrate etc. \\
Characterization by value or value complex & Conduct, display, perform, resolve, manage, verify, revise etc. \\
\hline Adapted from Ezeudu, Agwagah and Agbaegbu (1997).
\end{tabular}

Table 4. Levels of Psychomotor Domains and Action Words Used for Stating Assessment Questions

\begin{tabular}{ll}
\hline LEVEL & BEHAVIOURAL TERMS \\
\hline Perception abilities & Recognize, notice, categorize operate, answer correctly, copy group, \\
& detect, distinguish etc \\
Physical abilities & Manipulate, rotate construct, set up tighten, type, turn stand walk etc \\
Skilled movements & Catch, dance, kick, sew, type draw, demonstrate etc. \\
Non-discursive Communication & Compose, display, create, design express invent develop dramatize, \\
& portray, gestures, etc \\
\hline
\end{tabular}

Adapted from Ezeudu, Agwagah and Agbaegbu (1997).

\section{Scope}

This study is meant to ascertain the ability of the teachers to formulate good performance objectives based on Basic Science and Technology (BST) curriculum contents and state appropriate evaluation questions for assessing them. It is worthy to note that assessment is used in generic form in this study to cover all situations deliberately created by the teacher for the purpose of observing the pupils. The Scope of this study did not cover how the teacher teaches the lesson or relates with the students. Skills involved in establishing validity and reliability indices, procedures of marking and reporting of students are outside the focus. Grammatical, spelling and formatting errors were also ignored.

\section{Purpose}

The purpose of the study is to ascertain:

1) How well stated the specific objectives are

2) Relatedness of the assessment procedures to the stated objectives.

3) The coverage of the three domains of educational objectives by the specific objectives set by the teachers.

4) The coverage of the specific objectives by the assessment procedures.

5) The levels of the domains covered by the assessment procedures.

The following research questions guided the study:

1) What domains were covered by the specific objectives?

2) What domains were covered by the assessment?

3) What percentage of the assessment questions is unrelated to the specific objectives?

4) What levels of the domains are covered by the assessment?

5) How appropriately stated were the specific objectives?

\section{Method}

This is a descriptive survey study because the researcher collected data from a large sample drawn from a given population and described assessment features of the sample as they are at the time of the study without manipulating any independent variables of the study. However the findings from the sample were generalized to the population from which the sample was drawn. On the other hand, the study was carried out in order to make judgment about the value, 
worth or effectiveness of teachers in the area of assessment of learning outcomes. To this extent the study is an evaluation survey.

The research was carried out in one out of 27 Local Government Areas in Imo State. Nwangele Local Government Area, where the research was conducted had 192 teachers teaching the 6969 pupils spread across the 28 primary schools. (Local Government Education Authority, 18/02/14). At the time of this research teachers were to attend (once a week) a teacher professional development programme. The Local Government had two cluster centers for the programme. These centers served as meeting points between the researcher and the respondents. Each centre had 50 teacher participants drawn from 10 schools, 5 for each school giving a total of 100 teachers for the two centres. The researcher made arrangement on the first day of cluster meeting with the coordinator of the two centres to cause each participant to write one lesson plan on Basic Science and Technology (BST). Instructions given to the teachers read: write a lesson plan as you know it on any topic of your choice drawn from the Basic Science and Technology Curriculum for teaching in our next encounter. These lesson plans written by the teachers were the instruments for data collection. The researcher read each lesson plan paying particular attention to specific/behavioural objectives proposed for a given subject matter and the mode of assessment stated under the subheading 'evaluation'. A total of 93 copies of lesson plan were read and the results displayed under table 5 of the appendices were used to answer the research questions.

Table 5. Frequencies and Percentages (in Parentheses) of Specific Objectives and Evaluation Questions According to Domains

\begin{tabular}{llllll}
\hline & \multicolumn{3}{c}{ SPECIFIC OBJECTIVES } & \multicolumn{3}{c}{ EVALUATION QUESTIONS } \\
\hline Cognitive & Affective & Psychomotor & Cognitive & Affective & Psychomotor \\
\hline $172(79.3)$ & $06(2.8)$ & $39(18.0)$ & $104(79.4)$ & $4(3.1)$ & $23(17.6)$ \\
Total $=$ & 217 & & Total $=$ & 131 & \\
\hline
\end{tabular}

\section{Results}

A total of 217 specific objectives and 131 evaluation questions emanated from 93 copies of lesson plan prepared by the teachers. Out of the 217 specific objectives 172 giving $79.3 \%$ were in cognitive domains, affective domain had 6 or $2.8 \%$ while $18.0 \%$ of the objectives were set in psychomotor domains. In the same vein, 104 of the assessment questions amounting to $79.4 \%$ were in the cognitive domain. Affective had 3.1\% and Psychomotor 17.6\% respectively. Ideas that were not articulated in the objectives of the lesson but appeared in evaluation questions constituted 9.2 percent. These were described as assessment items that were not linked to the specific objectives. However, Objectives in cognitive that were not covered by assessment questions amounted to 31.3 percent.

\section{Discussion}

From the foregoing, it could be seen that Basic education teachers set objectives of their lesson more in the cognitive domain than Psychomotor and affective. Assessment of learning followed the same pattern. Assessment questions covered cognitive domains more than they covered the psychomotor and affective domains. This implied that the teachers' assessment skills in psychomotor and affective areas were defective. The result is that the pupils lacked necessary encouragement and motivation in developing affection for manipulative skills early in life. This had led to poor patronage of vocational and technical colleges and skills acquisition centre which the learners view as places for low achievers (Nwana 2011).

However, while the teachers' skills of stating objectives in behavioural terms using the appropriate action verbs were commendable, the evaluation questions had some blemishes. In some cases there were more objectives than assessment questions while in others there were more categories of assessment items that are not related to any specific objectives. A typical example could be cited here. A teacher planned to teach domestic animals with the following specific objectives: by the end of the lesson the pupils would be able to:

i. Mention the domestic animals.

ii. Say where they would be found.

Evaluation questions read, using the chart of animals the pupils would be asked to tell:

i. The animals they like best. 
ii. Where they could find domestic animals.

iii. The difference between animals and birds.

From the specific objectives of lesson it was clear that likes or dislikes of domestic animals by the pupils was irrelevant to the lesson. One would think that importance of domestic animals would be one of the main items in the assessment as indicated in the curriculum but this was omitted. However, the objectives were different from assessment. In another lesson plan based on the same topic the teacher stated in the objective that the pupils would be able to explain domestic animal but the assessment question read; Write out five domestic animals you know; mention their young ones. Write out suggests 'list' or mention which depicts knowledge level and differ from explain which means to show understanding. It was a lesson of single objective in which the assessment differ from the objectives. The teacher was simply digressing as lack of adequate planning was evident.

It was also observed that behavioural terms belonging to knowledge were used when assessment in the higher levels such as application analysis, synthesis and evaluation were desired. The same applied to objectives set using the terms classify, differentiate, sort, determines and discuss were wrongly used for lower tasks. That is assessment at lower level cognitives predominated. Ivowi (2009) had observed that it was wrong to treat as same questions that differ in task levels. The teachers appeared not to have adequate knowledge of the behavioural terms leading to indiscriminate use. Moreover, assessment of learning mostly at the knowledge level stifles independent thinking, creativity and keeps the learner passive during instruction (Emeka and Obialo 2010). The preponderance of assessment at the lower cognitive abilities of the learner had obvious demerits in encouraging rote learning and examination misconduct (Dimson 2007). Every learner is not good at regurgitation of facts especially the highly creative ones who were more comfortable in generating solutions in unique ways. In order to pass, they resort to cheating. Given that teaching and assessment go together it means that faulty assessment process are the direct results of poor planning and teaching. Lack of proper lesson planning was particularly evidence in the assessment. When the learner is unable to exhibit the behaviours expected, the reason for public outcry for quality assurance is not debatable but justified. The findings of this study tallied with the views of experts concerning the demerits of teacher-made tests (Ogomaka, 2009 Nwana, 2007 and Anikweze, 2012).

\section{Summary and Conclusion}

This study is meant to ascertain the assessment skills of teachers in connection with articulation of specific objectives of instruction and ability to ask the right questions in finding out if the objectives are achieved or not. This stems from the belief of the researcher that quality assurance of educational system should begin from classroom. If the classroom interaction is good, assessment results would be valid and the stakeholders would trust the system. Results had shown that teachers' assessment skills fell short of expectation and so would the teaching be. The harm in these is that the decisions taken based on assessment results are misleading because the results of assessment are not true reflection of the learning possessed by holders of the results.

The learners seemed to confirm this by their involvement in examination misconduct, inability to exhibit employable skills, and lack of engagement in meaningful ventures. It is the hope that the cluster teacher development programmes organized by the Universal Basic Education Commission (UBEC) would address these issues.

\section{Recommendations}

The following recommendations were made on the basis of findings of this study.

This study had waded into an area that is usually ignored. It is possible that the on-going teacher development programmes might not focus attention in this area. This is because teaching someone how to write a lesson plan is different from paying particular attention to how adequately given the items are in the various sub-headings of a given lesson plan. To this end, experts in test construction, measurement and evaluation are needed. The researcher recommends series of development programmes in this regard.

1) Lack of proper knowledge of the subject matter was apparent. The current arrangement whereby a teacher teaches all the subjects is no longer feasible. It is possible that those whose lesson plans were particularly bad were those who did not read science in their teacher education programme. No wonder Obioma (2013) recommended for a reform of teacher education programme and the discontinuation of a teacher teach-all-subjects arrangement in primary schools. This researcher joins in this recommendation.

2) Such development programmes that border purely on assessment of learning for practicing teachers should be 
handled by only experts in educational measurement and evaluation who should serve as resource persons. This should be done twice a year and all teachers should participate at every session.

3) Teacher education programmes should be reviewed to allow students write seminar papers or carry out micro research work on assessment of learning before they graduate.

4) The Universal Basic Education Commission (UBEC) officials who monitor the education programme should ensure they are accompanied by experts in educational measurement and evaluation who would be in better position to ascertain the appropriativeness of specific objectives in line with assessment.

\section{References}

Anikweze, C.M. (2012). Measurement and Evaluation for Teacher Education (3rd Edition.). Ibadan: Malijoe Soft Print.

Dibu Ojerinde. (2011). Public Examinations in Nigeria; A Collection of Papers, Chapter 9, Continuous Assessment Practice in Africa, pp. 193-203.

Dimson, J.N. (2007). Examination Malpractice: A Challenge to Development of Educational Sector in the $21^{\text {st }}$ Century. Journal of Women Academic (JOWACS), 4(i), 96-104.

Emeka, E.A., \& Obialo, F.K. (2010). Making Creativity a Priority in Nigeria's Quest for Quality Education. West African Journal of Education, xxx, 91-101.

Erinosho, S.Y. (2010). Quality Teacher Education in Nigeria. West African Journal of Education (WAJE), xxx, 102-111.

Ezeudu, S.A., Agwagah, U.N.V., \& Agbaegbu, C.N. (1997). Educational Measurement and Evaluation for Colleges and Universities. Nsuka: Cape Publishers.

Federal Government of Nigeria (FGN) (2004). National Policy on Education (4 ${ }^{\text {th }}$ Edition.). Lagos: NERDC.

Ivowi, U.M.O. (2009). A Critique on Protocol in the Assessment of Science Questions at the Senior School Certificate Examination. In O.C. Nwana (Ed)., Educational Measurement and Evaluation, Year Book 5. Nigerian Academy of Education (NAE) Pp. 261-280.

Iwu, A.O., Mbadiugha, C.N., Usor, C., \& Ikwuanubi E.N. (2011). Contemporary Issues and Method in Science Education. Owerri: Mile-Stone Publishers.

Nwana, O.C. (2007). Textbook on Educational Measurement and Evaluation. Owerri: Bomaway.

Nwana, O.C. (2011). Entrepreneurship Education and Challenges of National Transformation. Abuja International Journal of Education and Management Science (ABIJEMS), 1(2), 19-38.

Obioma, G. (2013). Transforming Teacher Education and Development for Global Competitiveness $25^{\text {th }}$ Convocation Lecture of Alvan Ikoku Federal College of Education Owerri, December.

Ogomaka, P.M.C. (2009). Teacher Effectiveness as Assessed by Students. In Nwana O.C. (Ed.), Educational Measurement and Evaluation, Year Book 5, Nigeria Academy of Education, pp. 79-102.

Okwilagwe, E.A. (2010). Whole School Evaluation as Imperative for Total Quality Management in School Evaluation Programmes. West African Journal of Education (WAJE), xxx, 112-124.

Teachers Registration Council of Nigeria (TRCN), (2004). Teachers Code of Conduct. Abuja.

Thorndike, R., \& Hagen, E. (1977). Measurement and Evaluation in Psychology and Educations. New York: John Wiley \& Sons.

Yoloye, E.A. (2009). Models of Educational Programme Evaluation. In O.C. Nwana (Ed), Evaluation, Measurement and Evaluation. Year 5 Nigerian Academy of Education, pp. 1-16. 